\title{
The effect of kinship on intraspecific competition in larvae of the poison frog Ameerega bassleri (Anura, Dendrobatidae)
}

\author{
Evan Twomey ${ }^{1}$, Victor Morales ${ }^{2}$ and Kyle Summers ${ }^{1}$ \\ 1 Department of Biology, East Carolina University, Greenville, NC, USA. E-mail: evan.twomey@gmail.com. \\ ${ }^{2}$ La Facultad de Ciencias Biológicas, Universidad Ricardo Palma, Lima, Peru.
}

\begin{abstract}
The effect of kinship on intraspecific competition in larvae of the poison frog Ameerega bassleri (Anura, Dendrobatidae). According to inclusive fitness theory, cooperation between related individuals should ameliorate the effect of intraspecific competition. However, close relatedness is also thought to increase similarity between individuals and therefore increase the risk of exploitative competition. Studies of the effects of kinship in larval amphibians have produced mixed results concerning these two hypotheses. We examined the effect of kinship on the mean and variation of mass after 30 days of growth in groups composed of either pure siblings or a mixture of five different sibships in a species of poison frog, Ameerega bassleri. We found no significant differences between sibling and mixed treatments with respect to mass or variation in mass. Our results are consistent with other studies in larval anurans which have found no differences between sibling and mixed treatments, suggesting that the effects of kin selection and genetic similarity between competitors may in some cases cancel each other out.
\end{abstract}

Keywords: Anura, Dendrobatidae, Ameerega bassleri, heterogeneous advantage, inclusive fitness, kin selection, Peru.

\section{Introduction}

Hypotheses of how relatedness affects the intensity of intraspecific competition have important implications for the evolution of social behavior, reproductive ecology, and habitat selection in many organisms, but debate exists as to what these effects are. The theories of kin selection and heterogeneous advantage produce opposing predictions about how relatedness affects intraspecific competition

Received 6 May 2008.

Accepted 13 October 2008.

Distributed December 2008.
(Hamilton 1964), and both have received empirical support in certain taxa (Griffiths and Armstrong 2001). On one hand, kin selection theory predicts that groups of closely related individuals should compete less intensely than unrelated individuals. Behaviors that reduce aggression and interference between kin may increase an individual's inclusive fitness and therefore be favored by natural selection. On the other hand, heterogeneous advantage predicts that because siblings are genetically similar, the potential for exploitative competition is higher because individuals in a group will overlap more in their resource use (Sammeta and Levins 1970). Consequently, intraspecific competition 
is predicted to be stronger between siblings than unrelated individuals.

Larval amphibians are valuable model organisms in studies of kin selection (see Waldman 1991) since they often form aggregations that may be composed of kin or non-kin, and larval success is often density dependent (Wilbur 1977). Although larval amphibians may preferentially associate with kin (Halverson et al. 2006), the adaptive significance of this behavior is complex and varies depending on the species or experimental conditions. For example, several studies (Jasienski 1988, Waldman 1991, Saidapur and Girish 2001, Girish and Saidapur 2003) have shown that individuals reared in sibling groups grow faster and/or achieve a larger mass at metamorphosis than those raised in mixed groups, results that support kin selection theory. Conversely, other studies have found that certain species grow better in mixed groups (Shvarts and Pyastolova 1970, Hokit and Blaustein 1994), supporting the heterogeneous advantage hypothesis, while others have found no difference in growth between sibling and mixed groups (Walls and Blaustein 1994, Gramapurohit et al. 2004).

In addition to affecting growth, some authors have suggested that genetic relatedness can influence variation in growth within a cohort. Waldman (1991) argued that sibling groups should experience higher variation in growth than mixed groups due to competitive restraint on the part of slow-developing 'runts'. If runts have a low probability of metamorphosis or survival, they may be able to facilitate growth of larger siblings by restraining their foraging intensity, redirecting predation risk, and, in extreme cases, sacrificing themselves to cannibalism. However, empirical studies testing this hypothesis have shown conflicting results. While some studies on fish and amphibians have found higher variation in growth in sibling groups (Beacham 1989, Waldman 1991), others have found the opposite result (Hokit and Blaustein 1997, Anderson and Sabado 1999,
Pakkasmaa and Aikio 2003, Saidapur and Girish 2001, Girish and Saidapur 2003).

We explored the effects of genetic relatedness on larval growth and variation in a species of poison frog, Ameerega bassleri (family Dendrobatidae). Like other species of Ameerega, females deposit eggs in leaf litter. A typical clutch is about 17 eggs (unpub. data), with eggs forming a single layer on the leaf. These eggs are attended by males, and upon hatching, the male will transport tadpoles on his back through the forest to small pools that form in low-lying areas. Pools generally range in volume from 6-46 L, and tadpole growth in this species is strongly affected by intraspecific competition (Twomey et al. 2008). Although schooling behavior of tadpoles has not been observed, adult $A$. bassleri are free to deposit their tadpoles in pools that may be occupied by kin or non-kin. Bearing that in mind, kinship effects on intraspecific competition could have ramifications not only for tadpole growth and fitness, but also for choice of tadpole deposition sites by adults in that they may attempt to deposit in pools containing related tadpoles (if kin are cooperative). The goal of the present study was to determine whether tadpoles raised in sibling groups grew faster than those raised in mixed-brood groups and to compare variances in growth between groups.

\section{Materials and Methods}

To evaluate the effect of relatedness on the mean and variation in the mass of larval $A$. bassleri, we set up a competition experiment in artificial pools where we manipulated relatedness of the competing tadpoles while maintaining a constant density of ten tadpoles per pool. We used two treatments in this experiment, a high-relatedness (sibling) treatment where all tadpoles in a pool were full siblings, and a low-relatedness treatment which contained two tadpoles from five different cohorts. In the low-relatedness treatment, any one tadpole had only one sibling present in the 
pool and was presumed to be unrelated to the other eight tadpoles. The sibling treatment and the low-relatedness treatment were replicated five and four times, respectively.

For this experiment, a total of 90 larval $A$. bassleri were collected from artificial pools set up in a field site near the town of Chazuta in Departamento San Martin, Peru $\left(6^{\circ} 32 ’ 35^{\prime}\right.$ S, $76^{\circ} 69^{\prime \prime}$ W) in June and July of 2008. While collecting egg clutches as opposed to tadpoles would have been ideal for kinship experiments, eggs are deposited in leaf litter and difficult to find. We were, however, able to confidently identify sibling and non-sibling tadpoles by frequently monitoring deposition activity in our artificial pools and taking into account time and place of deposition. Our artificial pools were arranged in eight distinct clusters which were spaced a minimum of $20 \mathrm{~m}$ apart; within clusters pools were arranged in five pairs, so that paired pools were less than 1 meter apart but different pairs were spaced 3-10 m apart. If tadpoles appeared in a single pool within a day of the time the pool was last checked, and were of the same stage, they were collected as siblings. It is unlikely that tadpoles collected from a single pool were of multiple parents because pools were checked frequently (3-5 times per week) and only freshly-deposited, early-stage tadpoles were used. Additionally, if two pools within a pair each received tadpoles, they were collected as siblings but only if the pools had been checked very recently, the tadpoles were of the same stage, and the sum of the tadpoles in both pools did not exceed the typical brood size for this species, which is 17 tadpoles (unpub. data.). We never considered tadpoles as siblings if they were collected from different pairs of pools or from different clusters. To collect unrelated tadpoles, we collected two putative siblings from a single cluster of pools, and repeated this in five different clusters to make a total of ten tadpoles. It is unlikely that tadpoles from different clusters were siblings, since clusters were widely spaced.
Once tadpoles were collected from the field site, they were transported to a nearby field station, assigned to the appropriate treatment, and reared in the experimental pools. These pools were ten liter plastic washtubs $\sim 30 \mathrm{~cm}$ in diameter and $15 \mathrm{~cm}$ deep. Tadpole density was therefore 10 tadpoles per liter, a density which is comparable to estimated field densities (typically 0.2-7.6 tadpoles per liter, Twomey et al. 2008). An experimental pool was initiated by filling it with water (chlorine-free water from a nearby creek) and three dried Cecropia leaves. Tadpoles were fed commercial rabbit chow ad libitum and weighed weekly to the nearest 0.01 $\mathrm{g}$ for 30 days. Tadpoles were weighed by removing them one-by-one with a small screen, blotting up excess water with a paper towel, and placing tadpoles on the scale one at a time. Fifty percent water changes took place weekly.

Growth data were analyzed by taking mean tadpole mass per pool after 30 days of growth, and performing a one-way ANOVA on these values between the two treatments. Due to the limited time frame for this study, pools were not run long enough to record metamorphosis data. However, rapid growth facilitates a short larval period, which may allow tadpoles to reduce risk of predation and desiccation (Wilbur 1980). We compared variation in growth after 30 days between the two treatments using two methods. First, we performed a Levene's test for homogeneity of variances. Second, we calculated the coefficient of variation for each pool and compared these values using a one-way ANOVA.

\section{Results}

At the start of the experiment, there was no significant difference in tadpole mass in the two treatments (kin: mean $=6.66 \mathrm{mg}$, st. dev. $=0.81$ $\mathrm{mg}$; mixed: mean $=6.26 \mathrm{mg}$, st. dev. $=1.46 \mathrm{mg}$; $\left.F_{1,7}=0.223, P=0.65\right)$. After 30 days of growth, there were no significant differences between treatments with respect to tadpole mass (kin: mean $=6.66 \mathrm{mg}$, st. dev. $=0.81 \mathrm{mg}$; mixed: 
mean $=6.26 \mathrm{mg}$, st. dev. $=1.46 \mathrm{mg}$ or coefficient of variation (Table 1). Twomey et al. (2008) found that 30 days of growth in $A$. bassleri was enough time for density effects to manifest differences in growth between treatments, and typically tadpoles began metamorphosing from experimental pools around 30 days (unpub. data). A Levene's test showed homogeneous variances in tadpoles at both the start of the experiment (Levene's $W=$ $1.48, P=0.227)$ and after 30 days of growth (Levene's $W=1.71, P=0.196)$. Distribution of tadpole mass is shown on Figure 1.

\section{Discussion}

Previous studies in tadpoles on the effect of relatedness on growth have shown varied results. While some studies have found no differences between sibling and mixed groups (Walls and Blaustein 1994, Gramapurohit et al. 2004), several studies have shown that siblings tend to grow better than mixed groups. For example, Girish and Saidapur (2003) found that sibling groups of Rana temporalis had a higher proportion of metamorphosing froglets and shorter larval periods than mixed groups, and

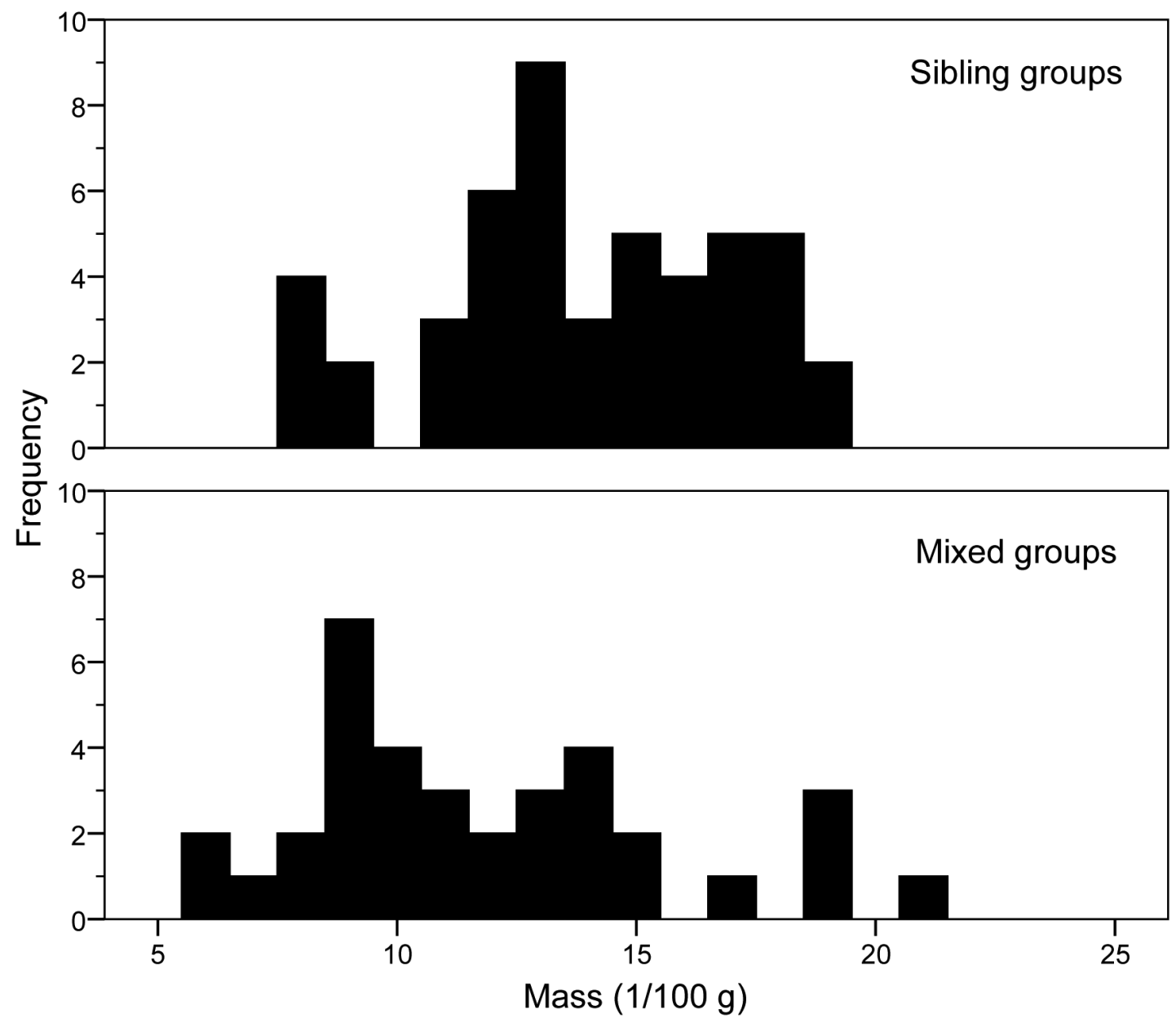

Figure 1 - Distribution of tadpole masses after 30 days of growth in sibling vs. mixed group treatments. 
Table 1 - ANOVA table for the effects of kinship on mass and growth variation.

\begin{tabular}{llcccc}
\hline Response variable & Source & $d f$ & SS & $F$ & $P$ \\
\hline \multirow{2}{*}{ Mass } & Between groups & 1 & 9.17 & 2.26 & 0.176 \\
& Within groups & 7 & 28.36 & & \\
& Total & 8 & 37.53 & & \\
\hline \multirow{2}{*}{ Coefficient of variation } & Between groups & 1 & 0.014 & 2.50 & 0.157 \\
& Within groups & 7 & 0.039 & & \\
& Total & 8 & 0.053 & & \\
\hline
\end{tabular}

that these differences were more pronounced in higher density treatments. Likewise, Waldman (1991) found that sibling groups of Bufo americanus reached larger mass at metamorphosis than mixed groups. Kin selection theory provides an elegant explanation of these results, where cooperation is predicted to evolve so long as the cost of the behavior for the actor is less than the product of the benefit to the recipient and their relatedness (Hamilton 1964). Cooperative behaviors may entail sharing reproductive duties (Emlen and Wrege 1988), predator-warning (Sherman 1977), or assistance in acquiring mates (Krakauer 2005). In tadpoles, mechanisms for cooperation may include competitive restraint (reducing exploitative competition), decreased interference with competitors (thereby increasing time available for foraging), or beneficial behaviors such as stirring up more periphyton than they can consume (Waldman 1991, Hokit and Blaustein 1997). However, these beneficial behaviors may be counteracted by genetic similarities between kin that increase the potential for exploitative competition, potentially canceling out effects of cooperation (Griffiths and Armstrong 2001). Since the effects of kin selection and heterogeneous advantage are thought to oppose each other, this may provide some explanation as to why we failed to detect significant differences in growth between the two treatments.
In contrast to previous studies that have shown higher variation in growth in sibling groups (Waldman 1991), we found that variation in mass after 30 days was not significantly different between sibling and mixed tadpole groups. Previous studies that have addressed the effect of kinship on growth variation have shown conflicting results. For example, in Rana temporaria, full-sib treatments had lower variation in growth rate and mass at metamorphosis (Pakkasmaa and Aikio 2003), while Hokit and Blaustein (1997) found that mass was more skewed towards small tadpoles in mixed groups compared to kin groups.

Deposition in the same pool by different adults has been observed in the field in $A$. bassleri $(N=4)$, and thus it is likely that tadpoles within pools face a mix of both kin and non-kin with some regularity. In these situations, any cooperation between kin that enhances their growth at the expense of non-kin in the same pool should be favored.

Here we might expect traits such as aggression toward non-relatives, or protection of resources from non-relatives to be favored. Additionally, one can consider kin groups within pools to be in competition with kin groups in other pools to exploit the resources available with the maximum efficiency and thoroughness. In this sense, cooperative traits that enhance the ability of all members of a kin group to exploit the available resources in an 
efficient manner should be favored by kin selection. Here, we might expect traits such as restraint in the rate of consumption of resources to be favored. This could enhance the efficiency with which resources are processed, providing an advantage to the entire kin group.

\section{Acknowledgements}

We thank D. Chalcraft, T. Lamb, and S. Curtis for helpful comments on this manuscript and support throughout this study. We thank J. Brown, J. Yeager, T. Kosch, K. Fieselman, and especially M. Guerra Panaijo for assistance in the field. We also thank M. Sanchez Rodriguez and M. Pepper who generously provided us with a place to work in Chazuta. This work was supported by funding to K. Summers from East Carolina University, the National Geographic Society (7658-04) and National Science Foundation (IOB-0544010) as part of another study. Research permits were obtained from the Ministry of Agriculture (INRENA) in Lima, Peru (Authorization No. 067-2007-INRENAIFFS-DCB).

\section{References}

Anderson, T. W. and B. D. Sabado. 1999. Effects of kinship on growth of a live-bearing reef fish. Marine Biology 133: 115-121.

Beacham, T. D. 1989. Effect of siblings on growth of juvenile coho salmon (Oncorhynchus kisutch). Canadian Journal of Zoology 67: 601-605.

Emlen, S. T. and P. H. Wrege. 1988. The role of kinship in helping decisions among white-fronted bee-eaters. Behavioral Ecology and Sociobiology 23: 305-315.

Girish, S. and S. K. Saidapur. 2003. Density-dependent growth and metamorphosis in the larval bronze frog Rana temporalis is influenced by genetic relatedness of the cohort. Journal of Biosciences 28: 489-496.

Gramapurohit, N. P., D. K. Veeranagoudar, B. A Shanbhag, and S. K. Saidapur. 2004. Relative influence of kinship and density on metamorphic traits of Tomopterna breviceps. Journal of Herpetology 38: 594-599.

Griffiths, S. W. and J. D. Armstrong. 2001. The benefits of genetic diversity outweigh those of kin association in a territorial animal. Proceedings of the Royal Society of London B 268: 1293-1296.

Halverson, M. A., D. K. Skelly and A. Caccone. 2006. Kin distribution of amphibian larvae in the wild. Molecular Ecology 15: 1139-1145.

Hamilton, W. D. 1964. The genetical evolution of social behaviour. Journal of Theoretical Biology 7: 1-52.

Hokit, D. G. and A. R. Blaustein. 1994. The effects of kinship on growth and development in tadpoles of Rana cascadae. Evolution 48: 1383-1388.

Hokit, D. G. and A. R. Blaustein. 1997. The effects of kinship on interactions between tadpoles of Rana cascadae. Ecology 78: 1722-1735.

Jasienski, M. 1988. Kinship ecology of competition: size hierarchies in kin and non-kin laboratory cohorts of tadpoles. Oecologia 77: 407-413.

Krakauer, A. H. 2005. Kin selection and cooperative courtship in wild turkeys. Nature 434: 69-72.

Pakkasmaa, S. and S. Aikio. 2003. Relatedness and competitive asymmetry - the growth and development of common frog tadpoles. Oikos 100: 55-64.

Saidapur, S. K. and S. Girish. 2001. Growth and metamorphosis of Bufo melanostictus tadpoles: effects of kinship and density. Journal of Herpetology 35: 249-254.

Sammeta, K. P. V. and R. Levins. 1970. Genetics and ecology. Annual Review of Genetics 4: 469-488.

Sherman, P. W. 1977. Nepotism and the evolution of alarm calls. Science 197: 1246-1253.

Shvarts, S. S. and O. A. Pyastolova. 1970. Regulators of growth and development of amphibian larvae. I. Specificity of effects. Soviet Journal of Ecology 1: 5862.

Twomey, E., V. Morales and K. Summers. 2008. Evaluating condition-specific and asymmetric competition in a species-distribution context. Oikos 117: 1175-1184.

Waldman, B. 1991. Kin recognition in amphibians. Pp 162-219 in P. G. Hepper (ed.), Kin Recognition. Cambridge. Cambridge University Press.

Walls, S. C. and A. R. Blaustein. 1994. Does kinship influence density dependence in a larval salamander? Oikos 71: 459-468.

Wilbur, H. M. 1977. Density-dependent aspects of growth and metamorphosis in Bufo americanus. Ecology 58 : 196-200.

Wilbur, H. M. 1980. Complex life cycles. Annual Review of Ecology and Systematics 11: 67-93. 